\title{
Problem drug use in a central London general practice
}

\author{
John Cohen, Alan Schamroth, Irwin Nazareth, Matthew Johnson, Stephen Graham, David Thomson
}

\begin{abstract}
Objective-To describe the profile of problem drug users presenting in general practice and to determine whether they can be cared for in general practice.

Design-Study of consultations by problem drug users.

Setting-Central London general practice.

Subjects -150 problem drug users presenting over two years.

Main outcome measures-Stopping drug use, alterations in lifestyle, obtaining paid work, and stopping drug related crime.

Results - Of the 150 patients, 111 were men and 39 women, and 106 were unemployed. 121 patients used heroin, 112 of whom injected. 145 patients accepted a methadone reduction programme and 81 completed it. A further $\mathbf{2 5}$ were stabilised on reducing doses of methadone, until places became available for them as inpatients at drug dependency units or rehabilitation projects.
\end{abstract}

Conclusion - Withdrawal programmes for patients who misuse drugs can be successfully managed in general practice.

\section{Introduction}

Problem drug use is a growing problem in many urban areas in Britain, Europe, and the United States. In Britain there is a serious shortage of specialist drug dependency units, and users will often consult with general practitioners at a time of crisis to get help with their misuse or complications arising from it, such as malnutrition, abscess formation, phlebitis, deep vein thrombosis, hepatitis, septicaemia, or HIV infection.

Little is known about the management of problem drug use in general practice; most of the published research has been based in drug dependency units. In 1986 a survey conducted on a sample of general practitioners in England and Wales showed that one in five had been consulted by a patient with opiate related problems in the previous month. ${ }^{12}$ The number of problem users seen by doctors varied widely depending on their geographical location and the attitudes of the doctors to the patients and their problems. ${ }^{3}$ Neville et al found that patients who misused drugs had higher consultation rates than matched controls, but if consultations relating to drug use were excluded, the rates were no different. ${ }^{4}$ There was no significant difference in the incidence of psychiatric disorder or disturbed family backgrounds in the drug misusing patients compared with the controls. ${ }^{3}$ Incidence of HIV infection was alarmingly high in studies of general practices in Edinburgh.

One of the greatest difficulties in managing drug using patients is ensuring that they are totally abstinent. Urine samples from a group of patients claiming to be abstinent from drugs after a detoxification programme in general practice showed that up to $18 \%$ had opiates in the urine. ${ }^{6}$ However, a follow up study on 12 patients treated for problem drug use in general practice in Bedford showed a definite change in the patients' attitudes; their lives became more stable and controllable, although not all of them withdrew completely from their addiction.

We conducted a study to discover the profile of the patients attending a general practice with drug problems and to find improved ways of providing the care they so obviously needed in a primary care setting.

\section{Subjects and methods}

The study was conducted in a surgery in London's West End from January 1988 to January 1990. The practice comprised two partners, an assistant, a trainee, a practice nurse, and two receptionists. The permanently registered list size is 3500 and around 900 temporary residents are seen each year. There is an annual turnover of around $28 \%$ with patients representing all social classes. The practice has an "open door" policy and will see anyone who claims to live locally.

We studied all patients misusing drugs presenting to us over the study period. Some of them came to us because we had been recommended by a member of their family, friend, or employer; some were referred by a needle exchange or drug project; and some came to seek help for complications associated with their habit. The practice policy was that all patients requesting help were seen and the options discussed.

Any medical problems, whether drug related or not, were managed on presentation, but patients requesting detoxification were initially referred to a drug project, if they had not been referred to us from a project. The projects were asked to assess needs and provide ongoing counselling, encouragement, and support.

On presentation patients were invited to complete a standard questionnaire, and some of the answers were clarified and extended during the first consultation. The questions collected information on age, accommodation, support systems, medical history, type of drugs used, method of use, dose, duration of use, previous attempts to stop, HIV infection, involvement in drug related crime, why they wished to stop taking the drugs now, and what type of drug projects they had consulted and when. They were also asked to provide a handwritten life history, summarising where they were born, where they spent their childhood and went to school, details of life after school, their introduction to drugs, and reasons for wanting to withdraw from drugs.

After this patients were examined briefly. Their height, weight, and blood pressure were measured and urine was tested for drugs. We looked for signs of intoxication, jaundice, abscesses, and needle tracks. Whenever possible patients were encouraged to bring a partner, relative, or friend who did not use drugs. It was made clear at the start that a methadone reduction
Correspondence to: Dr Cohen.

BMF 1992;304:1158-60 
programme would be offered and injectable drugs or long term prescribing were not available.

Methadone mixture $1 \mathrm{mg} / \mathrm{ml}$ was prescribed, starting at no more than $60 \mathrm{mg}$ a day for daily collection from the same pharmacist. Patients were seen weekly or fortnightly and their progress reviewed. The dose was reduced by $5 \mathrm{mg}$ at each visit. Random urine testing was done to encourage compliance.

If patients broke the agreement, or could not keep to it for any reason, we attempted to discuss their problems and, if possible, renegotiate the contract. If urine test results showed unprescribed drugs patients were invited to discuss the results and consider what should be done. Even if they were excluded from the programme, they were invited to return in a few weeks to consider what new measures should be taken. Most patients were serious in their attempts to defeat the habit. There was no stereotype and patients came from across the social spectrum.

Regular attendance at a drug project was expected during the programme. A realistic approach to remaining free from drugs was discussed towards the end of the programme. On completion of withdrawal the patients' records were examined to assess their attendance at the surgery and at the project, employment, and physical health (weight, nutritional status, clinical medical problems, and menstruation in women).

After completing the methadone reduction programme patients were encouraged to remain in contact with the surgery, but only a small number did so, allowing us to confirm by urine test that they were drug free. Many more remained in touch with the drug projects and we were able to obtain information and corroboration of patients' drug use from them. In some cases the information was obtained from partners, relatives, friends, and neighbours. All patients on our programme were notified to the Home Office drug addicts index.

\section{Results}

A total of 150 patients attended the surgery from January 1988 to January 1990 with drug problems. Table I shows their demographic details. The mean length of drug use was nine years for men and six years for women (range four months to 21 years). The main drug was heroin in 121 patients, dihydrocodeine in nine, methadone in eight, dextromoramide in seven, and buprenorphine in five. Forty one used other drugs at the same time. Of those using heroin, 112 injected it (92 men, 20 women) and nine smoked it (two men, seven women).

Forty two patients had been arrested for drug related offences and 15 had been in prison (mean stay 150 days). Ninety patients ( 79 men, 11 women) admitted to petty theft to support their habit, $46(28,18)$ admitted to

TABLE I - Demographic details of 150 drug misusing patients presenting to central London general practice

\begin{tabular}{lc}
\hline & No of patients \\
\hline Men & 111 \\
Women & 39 \\
Marital status: & 67 \\
Single & 34 \\
Married or cohabiting, both misusing drugs & 36 \\
Married or cohabiting, partner not using drugs & 12 \\
Divorced or separated & 1 \\
$\quad$ Widowed & 32 \\
Had children & \\
Employment at presentation: & 106 \\
Unemployed & 38 \\
Employed & 6 \\
Student & \\
Social class of employed (n=38): & 2 \\
I & 4 \\
II & 14 \\
III & 18 \\
IV &
\end{tabular}

TABLE II-Drug use in 150 patients three months after completing detoxification programme

No of patients

\begin{tabular}{lc}
\hline Not taking drugs, confirmed by urine test & 30 \\
Not taking drugs, not confirmed & 23 \\
Resident in rehabilitation facility and drug free & 21 \\
Receiving long term prescription from another doctor & 15 \\
$\quad$ or clinic & 26 \\
Misusing drugs but not injecting & 18 \\
Misusing drugs and injecting & 8 \\
In prison & 3 \\
Dead & 6 \\
Not possible to trace & \\
\hline
\end{tabular}

$\star$ Two patients had injected dextromoramide and one heroin.

begging, and $34(13,21)$ to prostitution. In all, 75 patients agreed to an HIV test or had already had one. Only 13 patients were infected with HIV.

\section{COMPLIANCE}

Of the 150 patients studied, two chose to stop drugs immediately, 145 chose methadone reduction, and three chose to be referred to a drug dependency unit. Eighty one of the 145 who started the methadone programme completed it and 64 did not. Women were more likely to complete the programme (31/39 (79\%) women compared with $65 / 111$ (59\%) men). Twenty five patients were stabilised on reducing doses of methadone until places were found for inpatient detoxification or rehabilitation programmes.

\section{AFTER COMPLETING PROGRAMME}

Table II shows the drug use by patients three months after they had completed the programme. Twenty of the 106 patients who had been unemployed at presentation had found regular paid work and 11 of the 17 women who had had amenorrhoea had started menstruating; two became pregnant shortly after completing the programme.

Twenty of the 48 patients who had admitted to being arrested for drug related offences had kept out of trouble with the police or the courts during and after the programme finished. Ten of these were completely free of drugs, four were still using but not injecting, and six were still using and injecting.

In all, 48 patients claimed to be still in touch with a drug project; 16 had completely stopped using drugs, 20 were still using but not injecting, and 12 still using and injecting. Most patients (109) put on weight during the programme, and 121 said they felt better and told us their family and friends said they looked much better. At presentation 48 patients were in contact with their family and 102 were not. By the end of the programme the number in contact with their family rose to 69 .

\section{Discussion}

It is difficut to determine exactly how succesful the progamme was. Some of our patients obtained additional supplies of drugs from other sources, although we tried to reduce "double scripting" by notifying the Home Office, contacting certain pharmacists, and random urine testing, etc. Our practice in the centre of London is not typical, but the study does show that general practice can care for the problem drug using population.

Only $13(18 \%)$ of our patients were known to be infected with HIV compared with $94 / 146(64 \%)$ in an Edinburgh study. ${ }^{8}$ The difference in the pattern of HIV infection is probably due to the different social settings. In Scotland large numbers of problem drug users live on large estates and share drugs, needles, and syringes as a social activity. In London most people who misuse drugs have only a few contacts with whom they buy and sell drugs but do not share needles. ${ }^{9}$

The initial consultations, acceptance, advice, and 
prescription for methadone mixture stabilised the chaotic existence of many of our drug misusing patients, reducing their need to carry out criminal or illegal activities to finance their habit and possibly keeping some of them out of prison or hospital. Once stabilised, a proportion were able to examine their lives and, in time, make the changes and adjustments needed to live without drugs.

Drug use presents huge costs to society arising from illegal activities, which require police, court, and prison staff and time; social security payments; lost revenue from taxes; and medical services to deal with the physical and psychological complications. It is therefore cost effective to stabilise a proportion of drug using patients. ${ }^{10}$

We dealt with the condition as a remitting one with a multifactorial aetiology. The main factors which led to drug misuse seemed to be availability of low priced drugs, unstable home background, personality defects, low self esteem, lack of stable relationships, rebellion and boredom, peer group pressure, and homelessness and reduced work opportunity. We found no evidence of any recognisable personality characteristic or type. For many patients relapses occurred with psychological stress, major life events, and social change.

\section{RUNNING THE PROGRAMME}

We decided on active management of the acute problem; medium term management with a methadone reduction programme and prevention of relapse by identifying possible precipitating factors; and long term rehabilitation. Overall, a policy of non-judgmental attitudes, compassion, and tolerance was required. We found no evidence of violence or intimidation, although there were several "dysfunctional consultations." It was important that our staff participated in our discussions and in setting the policy.

A few prescriptions were stolen, but the vigilance of local pharmacists and their tendency to telephone to confirm prescriptions was usually successful in picking up the culprits. Out of hours we made it clear that prescriptions or drugs lost would not be replaced. We received a few requests to assist patients in the evenings and at weekends, and we usually asked them to attend the surgery the next day unless there was a medical emergency. Several patients became seriously ill with subacute bacterial endocarditis. septicaemia, hepatitis, and infections of various kinds and required admission to hospital.

We felt a general lack of support from the local drug dependency services, social services, hospitals and other local general practitioners, and we met regularly to provide that support for ourselves. We strongly recommend that practitioners who see patients misusing drugs should have a support group.

\section{LONG TERM SUCCESS}

The long term outcome is always difficult to assess as these patients do not attend for follow up after the methadone reduction programme has finished and they are geographically mobile. By comparing the patients we knew to have successfully completed the programme with those who did not, however, it seemed that ability to keep appointments; absence of manipulative behaviour such as losing prescriptions and coming early for the next dose; opiate free urine test results (excluding methadone); daily consumption of $0.75 \mathrm{~g}$ of heroin a day or less at the start; and regular attendance at drug support and counselling agencies were all indicative of successful withdrawal. A criminal record was a negative factor

Factors which did not seem to influence the outcome were the route of administration of drugs, previous attempts at detoxification, length of misuse, age, and employment status.

We have shown that problem drug use can be managed in a general practice setting and identified factors which distinguish patients who would be more appropriately managed in a drug dependency unit.

We thank the staff of the Cleveland Street Needle Exchange and Hungerford, Angel, and Caravan Drug Projects, our staff, and the patients.

1 Glanz A, Taylor C. Findings of a national survey of the role of general practitioners in the treatment of opiate misuse: extent of contact with opiate practitioners in the treatment of
misusers. $B M \mathcal{F} 1986 ; 293: 486-8$.

2 Glanz A. Findings of a national survey of the role of general practitioners in the treatment of opiate misuse: views on treatment. $B M 7$ 1986;293:543-5.

3 Parker J, Gay M. Problem drug users known to Bristol general practitioners. $7 R$ Coll Gen Pract 1987;37:260-3.

4 Neville RG, McKelligan JF, Foster J. Heroin users in general practice: ascertainment and features. BMF 1988;296:755-8.

5 Robertson JR. Drug users in contact with general practice. BMF 1985;290: $34-5$.

6 Skidmore CA, Robertson JR. Simpson D, Jarvie DR. Toxicological screening in heroin users: implications for management of drug misuse. $\mathcal{f} R \mathrm{Coll} \mathrm{Gen}$ Pract 1987;37:397-9.

7 Martin E. Managing drug addiction in general practice - the reality behind the guidelines: discussion paper. $\mathcal{F} R$ Soc Med 1987;80:305-7.

8 Skidmore CA, Robertson JR, Robertson AA, Elton RA. After the epidemic: follow up study of HIV seroprevalence and changing patterns of drug use. follow up study of Hiv

9 Cook CLH, Lipsedge MS. Managing drug addiction in general practice. fR Soc Med 1987;80:782-3.

10 Cohen J, Schamroth A. The challenge of illicit drug addiction for general practice. Drug and Alcohol Dependence 1990;25:315-8.

(Accepted 23 February 1992)
The Apgar score-a record of heart rate, respiratory effort, reflex irritability, muscle tone, and colour-is a universally accepted method for assessing the wellbeing of newborn infants. The score is a part of the folklore of paediatrics and is not questioned as a true representation of the birth record. Consequently, when an article is published challenging the validity of established medical dogma minds remain closed and changes are difficult to establish.

In 1982 G S Sykes and his colleagues published in the Lancet an article entitled "Do Apgar scores indicate asphyxia?" They studied the relationship between blood gas analyses performed on cord bloods-venous and arterial-and the Apgar score and found little or no correlation. They concluded that the Apgar score did not usually reflect the degree of acidosis at delivery and its value as an index for asphyxial assessment should be questioned.

Since first reading this paper my reliance on the Apgar score has been severely shaken. I no longer accept the information that is purportedly supplied. My teachings on the subject of infant resuscitation echo these sentiments, recognising that calculating the score is a subjective exercise and can be influenced totally by observational error. All too often, when infants are critically asphyxiated, there is no time to record the score and the calculation is noted after the critical time it was there to assess. Doctors are scientists and should always keep an open mind, never closing it to a blind acceptance of what has been said and recorded in the past. - MAURICE WOOLDRIDGE is a consultan paediatrician in Tabuk, Saudi Arabia

Sykes GS, Johnson J, Answorth F, Molloy PM, Gu W, Stirrat GM, et al. Do Apgar scores indicate asphyxia? Lancet 1982;i:494. 